\title{
Medium term complications of endoscopic biliary sphincterotomy
}

\author{
P A WINSTANLEY, W R ELLIS, I HAMILTON, D J LINTOTT, AND A T R AXON \\ From the Gastroenterology Unit and Department of Diagnostic Radiology, The General Infirmary, Leeds
}

SUMmARY One hundred and fifteen patients were reviewed between 18 months and five years after successful endoscopic biliary sphincterotomy for choledocholithiasis, postcholecystectomy in $93(81 \%)$. Thirteen $(14 \%)$ postcholecystectomy patients and $11(50 \%, \mathrm{p}<0.001)$ with intact gall bladders are dead (cause of death was ascertained in each case). Of the others, 43 were interviewed and 48 completed a postal questionnaire. Stone free common ducts had been documented in $69(76 \%)$, presumed in $16(17 \%)$, and not achieved in six $(7 \%$, excluded from analysis). None of the responding patients had developed serious new problems. Current symptoms of those with and without gall bladders and those with 'documented' and 'presumed' duct clearance are similar. In no case has an episode of cholangitis since sphincterotomy been confirmed and only one patient has had documented recurrent duct stones. Continued incompetence of the sphincter was shown radiologically by the presence of bile duct gas in 14 $(41 \%)$ of 32 patients. These results suggest that medium term complications of endoscopic sphincterotomy are unusual.

Endoscopic sphincterotomy (ES) of the papilla of Vater is now an established procedure in the treatment of retained biliary duct stones following cholecystectomy. ${ }^{12}$ Complete duct clearance is often achieved, early complications are few, ${ }^{13-6}$ and the mortality and morbidity compare favourably, particularly in elderly patients, with those of surgical re-exploration. ${ }^{48}$ Endoscopic sphincterotomy has recently been recommended for patients with intact gall bladders who have duct stones, but are unsuitable for surgical treatment, usually because of age or infirmity. ${ }^{4}$ The long term sequelae of endoscopic destruction of the sphincter of Oddi, however, are not established; although there is now substantial published experience of endoscopic sphincterotomy, particularly in Europe,${ }^{589}$ the reports do not precisely distinguish late complications from early ones and from those of persistent stones. Two hundred and eighty eight patients underwent endoscopic sphincterotomy in this unit between September 1976 and July 1983, with duct clearance subsequently documented in $87 \%$ of those followed up. We have reviewed the subsequent progress of those of our early cases in which we are reasonably certain that the ducts were cleared of stones, in

Address for correspondence: Dr W R Ellis. Gastroenterology Unit. The General Infirmary. Leeds LS1 3EX.

Received for publication 21 August 1984 order to establish whether sequelae of endoscopic sphincterotomy can be expected in the medium term following a successful procedure.

\section{Methods}

PATIENTS

A period of 18 months was arbitrarily selected as the minimum interval after endoscopic sphincterotomy qualifying for the study (started in January 1983), providing a cohort of 130 patients who had undergone a successful endoscopic sphincterotomy between September 1976 and June 1981 (Fig. 1). Patients in whom endoscopic sphincterotomy had not been possible were excluded. All patients included were traced through the records departments of the referring hospitals, or our own notes, as appropriate. In six cases, no records could be found. Letters of enquiry were sent to the remaining 124 patients, but in nine cases no adequate reply was received (dementia in three cases, and change of address in six). Twenty four patients had died since the procedure, and the causes of death were ascertained from the NHS central register.

Forty eight patients completed a postal questionnaire, and 43 attended a clinic where the same questionnaires were completed by the authors (PAW and WRE), a blood sample was drawn for 


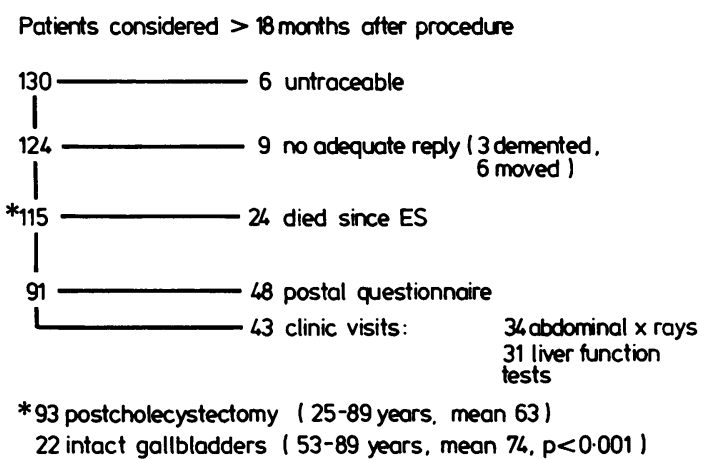

Fig. 1

estimation of bilirubin and alkaline phosphatase levels, and prone and supine radiographs were taken of the right upper quadrant of the abdomen.

In two cases endoscopic retrograde cholangiography (ERCP) was repeated because of persistent symptoms. The symptom groups were compared using the $\chi^{2}$ test with Yates's correction factor. The biochemical data were analysed using the rank sum test.

\section{Results}

Follow up information was obtained from 115 patients (Fig. 1). Patients with gall bladders in situ (GBS group) were significantly older than post cholecystectomy (PC group) patients $(\mathrm{p}<0.001$, rank sum test). Thirty two patients were known to have undergone surgical duct exploration before endoscopic sphincterotomy, 24 of whom were referred with T-tubes in place. Four of the remaining eight had had second admissions for surgery after cholecystectomy. Excluding those who had died and six in whom persistent calculi were documented following endoscopic sphincterotomy (Fig. 2), detailed review, comprising at least a completed questionnaire, was possible in 85 patients, 11 in the GBS group and 74 in the PC group.

The interval since endoscopic sphincterotomy was less than two years in 14 cases, between two and three years in 34, between three and four years in 18 , and over four years in 19.

In 69 cases $(81 \%)$ clearance of stones from the ducts had been confirmed, but in 16 cases (19\%), although endoscopic sphincterotomy was successful, allowing passage of a $12 \mathrm{~mm}$ balloon, stone extraction was not carried out, nor was a follow up examination (usually those in the GBS group). In these cases stone passage could only be presumed (Fig. 2).

A total of 28 patients had developed new prob-

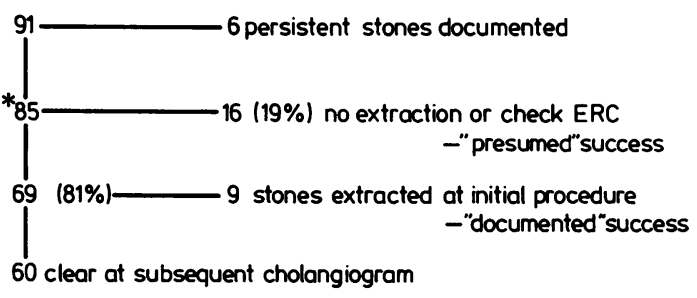

*74 postcholecystectomy 11 intact gallbladders

Fig. 2

lems since endoscopic sphincterotomy (Table 1). Most patients had experienced improvement in their symptoms as a result of endoscopic sphincterotomy (Table 2). There was no significant difference in the degree of improvement between the PC and GBS groups, nor between the 'documented' and 'presumed' successes. In response to direct questions, five patients (all PC) admitted to febrile episodes since endoscopic sphincterotomy. Four patients (three PC, one GBS) said they had shivering attacks and two (one in each group) claimed to have been jaundiced. None of these patients (seven in all, five with documented and two with presumed duct clearance) had consulted a doctor with these symptoms and no diagnostic tests had been performed at the time, thus no documented episode of cholangitis can be confirmed. One of these patients, however, did later have investigations and a surgical duct exploration at which recurrent stones were found, following the demonstration of stone free ducts after endoscopic sphincterotomy two years previously.

In 31 patients (four GBS and 27 PC) biochemical data were available both from before endoscopic

Table 1 New problems since sphincterotomy

\begin{tabular}{lll}
\hline & $\begin{array}{l}\text { Gall bladder } \\
\text { in situ }\end{array}$ & $\begin{array}{l}\text { Post } \\
\text { cholecystectomy }\end{array}$ \\
\hline Heartburn & 0 & 5 \\
Constipation & 0 & 3 \\
Flatulence & 0 & 3 \\
Abdominal discomfort & 0 & 7 \\
Diarrhoea & 0 & 2 \\
Weight gain & 0 & 1 \\
Dizziness & 0 & 1 \\
Sore throat & 1 & 1 \\
Mobility problems & 0 & 1 \\
Urinary frequency & 0 & 4 \\
Diabetes mellitus & 1 & 0 \\
Haemorrhoids & 1 & 0 \\
Cough (bronchial carcinoma) & 1 & 0 \\
Total number of patients & 4 & 24 \\
\hline
\end{tabular}

$(p>0.5)$ 
Table 2 Questionnaire results: assessment by patients of the effects of endoscopic sphincterotomy on symptoms

\begin{tabular}{lllll}
\hline & $\begin{array}{l}\text { Post- } \\
\text { cholecys- } \\
\text { tectomy }\end{array}$ & $\begin{array}{l}\text { Gall } \\
\text { bladder } \\
\text { in situ. }\end{array}$ & $\begin{array}{l}\text { Docu- } \\
\text { mented } \\
\text { success }\end{array}$ & $\begin{array}{l}\text { Pre- } \\
\text { sumed } \\
\text { success }\end{array}$ \\
\hline Asymptomatic & 43 & 3 & 42 & 5 \\
Much better & 22 & 4 & 19 & 7 \\
Little better & 4 & 3 & 4 & 4 \\
Unchanged & 5 & 1 & 4 & 0 \\
Worse & 0 & 0 & 0 & 0 \\
Total & 74 & 11 & 69 & 16 \\
& $(\mathrm{p}>0 \cdot 10)$ & \multicolumn{3}{c}{$(\mathrm{p}>0 \cdot 05)$} \\
\hline
\end{tabular}

sphincterotomy and from the follow up clinic. Serum bilirubin and alkaline phosphatase were significantly lower after endoscopic sphincterotomy $(p<0.01)$ and, except for the phosphatase in two cases, had returned to normal levels (Fig. 3).

Thirty four of the patients who attended the clinic underwent prone and supine radiographs of the right upper quadrant of the abdomen. In 14 cases $(41 \%)$ bile duct gas was shown. In the first 10 cases radiographed ultrasound examination was also requested, but assessment of the presence or absence

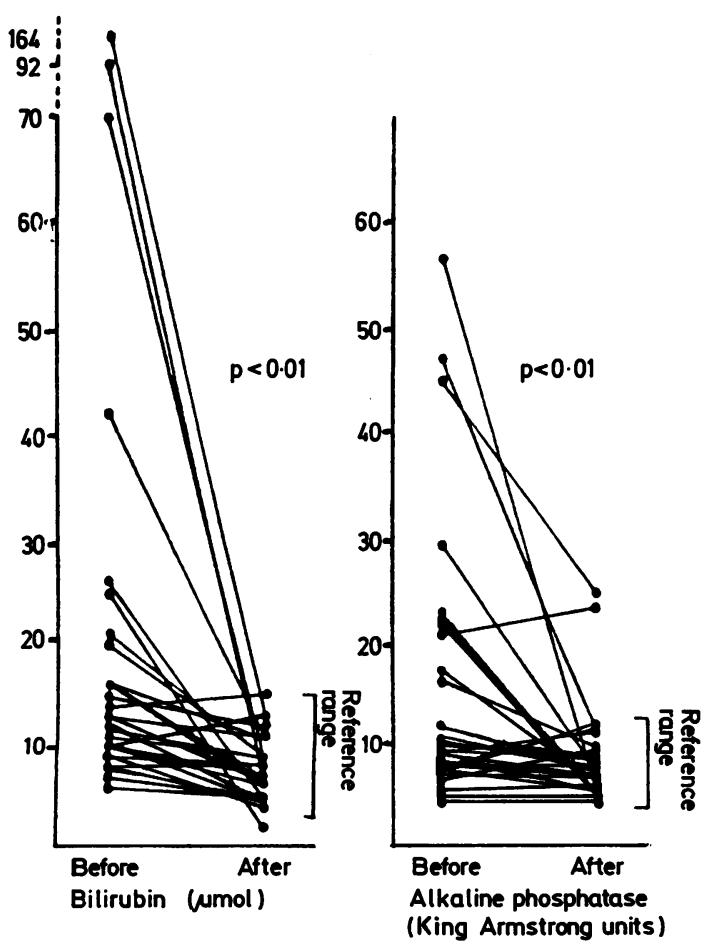

Fig. 3 of stones proved impossible because of duct gas in all 10 , although gas was visible in only five of these on the radiographs. Two of the patients interviewed had symptoms unchanged by endoscopic sphincterotomy, and agreed to repeat ERC. Apart from the characteristic juxtapapillary fistula, no abnormality was detected in either case.

No patient in the series had been readmitted to hospital with acute biliary disease or pancreatitis since endoscopic sphincterotomy, and none of the GBS patients has undergone cholecystectomy. Elective duct exploration was carried out in the patient mentioned above, who is the only instance of documented recurrent duct stones. Three other patients (all PC) were operated on, by referring surgeons, for persistent jaundice, within six weeks of endoscopic sphincterotomy, and during the same admission. No stones were found in these cases and jaundice settled in two: the third patient died postoperatively with gastrointestinal bleeding.

Two other deaths occurred soon after endoscopic sphincterotomy, one from continuing cholangitis and septicaemia, the other from haemorrhage five days after endoscopic sphincterotomy probably associated with stone passage (both GBS). A further patient died one month after endoscopic sphincterotomy of carcinoma of the pancreas and another after six months of primary biliary cirrhosis (both GBS patients). The remaining deaths occurred between one year and five years from endoscopic sphincterotomy and were due to non-biliary disease in all cases as far as can be ascertained. In five cases, broncho pneumonia is given as the cause of death, but the coincident conditions of cerebral infarction (four cases) and gross congestive cardiac failure (one case) do not suggest an acute non-localising biliary infection as the underlying cause. There is a significant excess of deaths in the GBS group (11/22) as compared with the PC group (13/93, $\mathrm{p}<0 \cdot 001)$.

\section{Discussion}

The possible long term sequelae of endoscopic sphincterotomy include bacterial contamination of the ducts, recurrent or persistent cholangitis, stenosis of the papilla of Vater producing recurrent obstruction, and pancreatitis. Our experience suggests that these are not major problems in practice. Seven patients, when questioned directly, admitted to symptoms which might be attributable to cholangitis after endoscopic sphincterotomy, but none had diagnostic investigations at the time, and all refused further ERC to exclude persistent calculi. In the one patient who was subsequently investigated, recurrent stones were found. Apart from these, no patients have had symptoms suggestive of further 
duct obstruction, and liver function tests were normal in all but two cases at the follow up clinic. Thus clinical papillary stenosis is not a problem we have encountered, although it has been reported in small numbers of patients in a recent large German series. ${ }^{7}$ We have never undertaken endoscopic sphincterotomy solely for papillary stenosis or 'Oddi spasm' as is done in some European ${ }^{7}$ and American ${ }^{8}$ centres, so restenosis is perhaps less likely in our cases.

The evidence from those of our patients who had plain abdominal radiographs performed suggests that in many cases the sphincter never recovers. In this connection, it should be noted that although gas was observed in the biliary system in only $41 \%$ of cases, it may have been present and undetected in many more, as suggested by the results of the ultrasound examinations. Destruction of the sphincter mechanism by endoscopic sphincterotomy is therefore likely to be permanent.

This outcome is potentially useful in patients with intact gall bladders in whom stones may persist or recur, and again migrate into the ducts. It is our impression, however, that endoscopic sphincterotomy is more hazardous in GBS patients, possibly because they are usually selected on grounds of co-existing illness or old age. In the present series, the two early post procedure deaths were both in such patients. In our total series to date, three of the four early procedure related deaths and the majority of the patients with significant bleeding after endoscopic sphincterotomy have had intact gall bladders.

Our experience suggests that in the medium term, in patients whose biliary trees are successfully cleared of stones, serious sequelae are rare after endoscopic sphincterotomy. Comparison with the results of surgical treatment is difficult in this context since few recent long term follow up studies after surgery are available. Cotton ${ }^{10}$ has recently pointed out that the results of endoscopic sphincterotomy should properly be compared with those of second or third surgical biliary procedures, because almost all younger endoscopic sphincterotomy candidates have already had a cholecystectomy, in the majority with exploration of the duct; as such they are already failures of surgery in the first instance. Published experience of complications and recurrence rates for stones after second biliary operation vary very widely, ${ }^{10}$ but the long term results may be considerably improved by incorporating a permanent drainage procedure. ${ }^{11}$ Further careful follow up of patients treated both endoscopically and surgically is required to resolve this question.

In the case of elderly subjects, the short term outlook is of greater importance and because the immediate surgical risks are greater in this group 78 endoscopic sphincterotomy is now increasingly used. ${ }^{410} 12$ Where the gall bladder is intact, endoscopic sphincterotomy alone seems to be adequate treatment for many older patients; our experience, like that of others ${ }^{1} 1213$ suggests that a subsequent requirement for cholecystectomy is unusual in the medium term and that death is usually from unrelated causes.

We wish to thank Mr N C Smeeton MSc (University of Leeds), Mr D Simpson (Leeds Registration of births, marriages, and deaths), and the staff of the NHS central register, Southport.

\section{References}

1 Safrany L, Cotton PB. Endoscopic management of cholelithiasis. Surg Clin N Am 1982; 62: 825-36.

2 Safrany L. Duodenoscopic sphincterotomy and gallstone removal. Gastroenterology 1977; 72: 338-43.

3 Cotton PB, Vallon AG. British experience with duodenoscopic sphincterotomy for treatment of bile duct stones. Br J Surg 1981; 68: 373.

4 Mee AS, Vallon AG, Croker JR, Cotton PB. Nonoperative removal of bile duct stones by duodenoscopicsphincterotomy for treatment of bile duct stones. Br Med J 1981; 283: 521-3.

5 Reiter JJ, Bayer HB, Mennicken C. Results of endoscopic papillotomy, a collective experience from nine endoscopic centres in West Germany. World $J$ Surg 1978; 2: 505-7.

6 Neuhaus B, Safrany L. Complications of endoscopic sphincterotomy, and their treatment. Endoscopy 1981; 13: 197-99.

7 Seifert E, Gail K, Weismüller J. Long term results after endoscopic sphincterotomy. Dtsch Med Wochenschr 1982; 107: 610-4.

8 Siegel JH. Endoscopy and papillotomy in diseases of the biliary tract and pancreas. J Clin Gastroenterol 1980; 2: 337-47.

9 Rösch W, Riemann JF, Lux G, Linder HG. Long term follow up after endoscopic sphincterotomy. Endoscopy 1981; 13: 152-3.

10 Cotton PB. Endoscopic management of bile duct stones (apples and oranges). Gut 1984; 25: 587-97.

11 Lygidakis NJ. Surgical approaches to recurrent choledocholithiasis. Am J Surg 1983; 145: 633-9.

12 Escourrou J, Cordova JA, Lazorthes F, Frexinos J, Ribet A. Early and late complications after endoscopic sphincterotomy for biliary lithiasis with and without the gall bladder 'in situ'. Gut 1984; 25: 598-602.

13 Neoptolemos JP, Carr-Locke DL, Fraser I, Fossard DP. The management of common bile duct calculi by endoscopic sphincterotomy in patients with gallbladder in situ. Br J Surg 1984; 71: 69-71. 